

\title{
LA REFORMA DEL ESTATUTO DE AUTONOMÍA PARA CATALUÑA. REPERTORIO BIBLIOGRÁFICO
}

\author{
ESPERANZA GÓMEZ CORONA \\ Profesora Contratada Doctora de Derecho Constitucional \\ Universidad de Sevilla
}

\author{
SUMARIO \\ I. Cuestiones preliminares \\ II. El procedimiento de reforma estatutaria \\ III. El nuevo Estatuto de Autonomía de Cataluña: \\ aspectos generales \\ IV. Competencias \\ V. Financiación \\ VI. Derechos estatutarios \\ VII. Control de constitucionalidad \\ VIII. Autonomía local \\ IX. Lengua \\ X. Documentos
}

\section{CUESTIONES PRELIMINARES}

En los últimos años, pocas cuestiones han suscitado tanta polémica social, política y jurídica como la reforma del Estatuto de Autonomía de Cataluña, que inauguraría lo que algunos han considerado un «segundo Estado de las Autonomías» ${ }^{1}$ y que habría continuado con las reformas producidas entre los años 2006 y $2007^{2}$.

La propuesta de reforma, que contó con el respaldo del $90 \%$ de la Cámara catalana ${ }^{3}$, sería profundamente rebajada en las Cortes Generales, en un proceso político muy com-

1. De la apertura de esta segunda etapa habla Cruz Villalón, P., «La reforma del Estado de las Autonomías», Revista d'Estudis Autonòmics i Federals, 2, 2006, pág. 84.

2. El proceso de reforma estatutaria se inicia con la modificación del EA de Valencia por L.O. 1/2006, de 10 abril y al que siguieron los de Cataluña (L.O.6/2006, de 19 de julio), Islas Baleares (L.O. 1/2007, de 28 de febrero), Andalucía (L.O. 2/2007, de 19 de marzo), Aragón (5/2007, de 23 de abril) y Castilla y León (L.O. 14/2007, de 30 de noviembre).

3. Únicamente el Partido Popular se opuso en el Parlamento catalán. 
plejo que pudo culminar con éxito gracias al acuerdo del Partido Socialista con CiU, al que posteriormente se unió ICV, pero que contó con la oposición del tercer socio del gobierno tripartito catalán que había impulsado la reforma, ERC, además de EA y del Partido Popular. Por primera vez entre nosotros, un Estatuto de Autonomía se aprobaba sin el consenso de los dos principales partidos de ámbito estatal.

Las críticas al nuevo texto se centran no sólo en cuestiones puntuales sino que alcanzan a su misma filosofía. Se argumenta que, desde un punto de vista material, constituye una auténtica reforma constitucional. En esta línea, el grupo parlamentario popular en el Congreso llegó a plantear un recurso de amparo contra el Acuerdo de la Mesa que calificaba el texto como reforma de un Estatuto de Autonomía, argumentando que debería tramitarse como una reforma constitucional. El Tribunal Constitucional desestimó esta pretensión en la STC 85/2006, de 25 de marzo.

Las principales características del texto aprobado por las Cortes Generales podrían resumirse como siguen ${ }^{4}$ :

a) Reforzamiento de la identidad propia de Cataluña. El Preámbulo del nuevo Estatuto de Autonomía destaca que «el Parlamento de Cataluña, recogiendo el sentimiento y la voluntad de la ciudadanía de Cataluña, ha definido de forma ampliamente mayoritaria a Cataluña como nación. La Constitución Española, en su artículo segundo, reconoce la realidad nacional de Cataluña como nacionalidad». Asimismo, el texto expresa no sólo el derecho sino el deber de todas las personas en Cataluña de conocer las dos lenguas oficiales en dicha Comunidad Autónoma (art. 6 EAC), hace mención expresa a los derechos históricos del pueblo catalán, en el que se fundamenta el autogobierno de Cataluña (art. 5 EAC), se refiere a la bandera, la fiesta y el himno como «símbolos nacionales» de Cataluña (art. 8 EAC) y reconoce a Arán como «realidad occitana dotada de identidad cultural, histórica, geográfica y lingüística» (art. 11 EAC). La Propuesta aprobada por el Parlamento catalán destacaba en su artículo 1 que «Cataluña es una nación».

b) Reconocimiento de derechos específicos en el Estatuto de Autonomía. Este hecho, que sería luego imitado por otros textos estatutarios ha abierto un interesante debate doctrinal acerca de la idoneidad de los Estatutos de Autonomía para incluir catálogos de derechos.

c) El reforzamiento y la extensión de las competencias autonómicas. Entre los argumentos esgrimidos a favor de la necesidad de una reforma estatutaria se incluía la percepción según la cual las competencias autonómicas estaban siendo limitadas en la práctica por el uso extensivo de las competencias horizontales reconocidas al Estado, así como por la interpretación que el mismo otorgaba a las materias objeto de su competencia.

El Estatuto de Autonomía para Cataluña inaugura una práctica, que luego sería seguida por otros Estatutos, como el de Andalucía, que se ha denominado de «blindaje competencial». Esta técnica consiste en la definición de las competencias que puede ejercer la Comunidad Autónoma, detallándolo al máximo. De esta manera, se enumeran las distintas materias sobre las que la Comunidad Autónoma tiene com-

4. A este respecto, Carrasco Durán, M.; Gómez Corona, E., «2006. El año de reforma de los Estatutos», Crónica Jurídica Hispalense, 5, 2007. 
petencia y se detallan con enorme minuciosidad cada una de las potestades que la Comunidad puede ejercer sobre ellas.

d) Reforzamiento institucional de la Generalidad. El nuevo texto reconoce al Gobierno de la Generalidad la facultad de dictar Decretos legislativos y Decretos-leyes (arts. 63 y 64 EAC), competencias en materia de Poder Judicial y Administración de Justicia (arts. 95 a 109 EAC), incluyendo la creación de un Consejo de Justicia de Cataluña (arts. 97 a 100 EAC), así como la asunción de un importante papel en relación con la Unión Europea (arts. 184 a 192 EAC) y la acción exterior (arts. 193 a 200 EAC).

e) El reforzamiento de la participación de la Comunidad Autónoma en el desarrollo de políticas que son competencia del Estado y en el nombramiento de los miembros de órganos políticos y administrativos del Estado.

f) La reforma del sistema de financiación de la Comunidad Autónoma. En este ámbito se plantea si un Estatuto de Autonomía puede prever el sistema de financiación autonómica con el grado de detalle con el que se contiene en el Estatuto Catalán o si se estaría invadiendo el contenido reservado por la Constitución a la Ley Orgánica de Financiación de las Comunidades Autónomas.

El nuevo Estatuto de Autonomía de Cataluña sería objeto de siete recursos de inconstitucionalidad. Entre ellos, los planteados por 99 diputados del Grupo Parlamentario Popular del Congreso y por el Defensor del Pueblo. La resolución del primero de ellos, largamente esperada, ha estado precedida de reiteradas filtraciones a la prensa sobre el contenido de las sesiones deliberativas y las posiciones de los distintos miembros y de un inusual juego de recusaciones frente a distintos magistrados.

Finalmente, la STC 31/2010 resuelve el recurso planteado por los populares y declara inconstitucionales algunos preceptos estatutarios en una resolución de más de 800 páginas. De acuerdo con el fallo, 14 disposiciones son declaradas inconstitucionales, otras 27 son objeto de una interpretación conforme de constitucionalidad, de acuerdo con la cual sólo son constitucionales si se interpretan en el sentido expuesto en los correspondientes fundamentos jurídicos a los que remite el fallo. Además, las referencias a Cataluña como nación contenidas en el Preámbulo se consideran carentes de eficacia interpretativa. Los demás artículos impugnados, de un total de 120, se declaran conformes a la Constitución aunque introduciendo matices que terminan por acotar el sentido de muchos de ellos 5 .

La crispación política que ha rodeado todo el proceso tendría uno de sus puntos álgidos en la respuesta inusitada a la resolución del Alto Tribunal: una manifestación encabezada por las mismas autoridades catalanas ${ }^{6}$.

A pesar de que la reforma es relativamente reciente, la doctrina se ha ocupado muy intensamente del proceso de aprobación del nuevo Estatuto de Autonomía para Cataluña. En las páginas que siguen tratamos de ofrecer una selección que, si bien no pre-

5. Castellá Andreu, J. M., «La sentencia del Tribunal Constitucional 31/2010, sobre el Estatuto de Autonomía de Cataluña y su significado para el futuro del Estado Autonómico», Documentos de la Fundación Ciudadanía y Valores,2010 pág. 1. www.funciva.org

6. La crispación política, presente en todo el proceso de reforma, se hace patente en actuaciones como la recogida de firmas llevada a cabo por el Partido Popular, antes de la aprobación definitiva del texto, para solicitar la celebración de un referéndum a nivel nacional sobre el Estatut. 
tende ser exhaustiva, sí trata de ser representativa. Para hacer más fácil su manejo, se ha organizado la literatura en una serie de epígrafes que se centran en algunas de las cuestiones más relevantes.

Conviene destacar que en este repertorio se incluyen únicamente aquellos trabajos referidos de manera específica al proceso de reforma llevado a cabo en Cataluña y no aquellos que abarcan de manera general el proceso de reforma iniciado en 2006. De estos últimos, únicamente se han incluido aquellos en los que el estudio de la reforma del Estatut ocupa un lugar significativo, a pesar de disponer de un objeto de análisis más amplio.

En el apartado II, dedicado al procedimiento de reforma, se incluyen aquellos trabajos que se centran o bien en la propuesta de reforma presentada por el Parlamento de Cataluña y que luego sería enmendada en las Cortes Generales o en cuestiones puntuales relativas a la tramitación de la reforma en sí misma considerada.

A continuación, en el apartado III, se incluyen aquellos trabajos que abordan el estudio del nuevo Estatuto de Autonomía para Cataluña desde una perspectiva general.

En el epígrafe dedicado al estudio de las competencias (IV) se ha considerado necesario distinguir entre aquellos trabajos realizados sobre la propuesta de reforma (IV.1) de aquellos que se llevan a cabo una vez aprobado el nuevo texto (IV.2).

También ha estado muy presente en el debate académico y doctrinal, además de político, la espinosa cuestión de la financiación autonómica. A los trabajos dedicados a la misma, aunque centrados en el caso catalán, se ha dedicado el epígrafe V.

Debido al debate sostenido durante todo el proceso de reforma y hasta el pronunciamiento del Tribunal Constitucional acerca de la oportunidad y viabilidad de un control de constitucionalidad de los Estatutos de Autonomía ratificados en referéndum, se incluye un epígrafe VI que distingue a su vez entre la pertinencia de este control y el estudio de la STC 31/2010, en la que el Tribunal Constitucional se pronuncia sobre la constitucionalidad del Estatut.

A continuación (VII) se aborda la polémica cuestión de la inclusión de derechos en los Estatutos de Autonomía. Dado que este debate se inicia con la reforma del Estatuto de Cataluña, se incluyen algunos trabajos que afrontan la cuestión desde una perspectiva general.

También la lengua ha cobrado un importante protagonismo en este proceso, por lo que se incluyen los estudios sobre esta cuestión en el epígrafe VIII.

Asimismo, la autonomía local está presente en los trabajos que analizan la reforma del Estatuto de Autonomía de Cataluña. En este apartado (IX), se incluyen tanto cuestiones generales como asuntos relativos a la financiación de las entidades locales.

Para terminar, se contiene un apartado X dedicado a «documentos». Este último se incluye dado que las instituciones catalanas han elaborado multitud de informes y documentos de mucha utilidad para el estudio de todo el proceso de reforma estatutaria.

\section{EL PROCEDIMIENTO DE REFORMA ESTATUTARIA}

AJA, E., «La proposición de reforma del Estatuto de Cataluña», en López RAMÓN, F. (ed.), De la reforma estatutaria, Zaragoza, Gobierno de Aragón, 2005. 
Albertí Rovira, E., «El proceso de reforma del Estatuto de Autonomía de Catalunya», en Garrido Mayol, V.; Catalá i Bas, A.; García i Mengual, F. (coords.), Modelo de Estado y Reforma de los Estatutos, Valencia, Fundación Profesor Manuel Broseta, 2007.

Argullol Murgadas, E., «El desarrollo de la autonomía: entre la reforma y la relectura de la Constitución y del Estatuto de Autonomía», en Desarrollar el autogobierno, Madrid, Península, 2002.

Balaguer Callejón, F.; Medina Guerrero, M.; Saiz Arnaiz, A.; García Roca, F. J., Conclusiones generales del dictamen sobre la propuesta de reforma del Estatuto de Cataluña, Madrid, PSOE, 2005.

Barceló I Serramalera, M., (et al.), Autogovern i reforma de l'Estatut d'autonomia de Catalunya: comentari a la proposta de reforma de l'Estatut d'autonomia de Catalunya, Barcelona, Institut d'Estudis Autonòmics, 2006.

Bueno Armijo, A. M., Rodriguez Portugués, M. A., «El fumus boni iuris como criterio contrario al solicitante de medidas cautelares: ¿un traidor entre los aliados? Comentarios a los autos del TSJ de Cataluña, de 16 y 17 de junio de 2006, sobre suspensión cauteladísima del referéndum sobre la reforma del Estatuto de Autonomía de Cataluña», Revista de Administración Pública,172, 2007.

CAbellos Espiérrez, M. A., «Crónica sobre el actual proceso de reforma de los Estatutos de Autonomía: Cataluña», Revista General de Derecho Constitucional, 1, 2006.

Carreras, F., «El proyecto de nuevo Estatuto de Cataluña», en Garrido Mayol, V.; CAtalá i Bas, A.; García i Mengual, F. (coords.), Modelo de Estado y Reforma de los Estatutos, Valencia, Fundación Profesor Manuel Broseta, 2007.

Carreras, F., «Reflexiones sobre la propuesta de nuevo Estatuto de Cataluña», Teoría y Realidad Constitucional, 16, 2005.

Carreras, F., «El nuevo estatuto frente a la Constitución», Claves de la Razón Práctica, $158,2005$.

Carrillo LóPez, M., «L'Estatut, l'autonomia i el futur», Nous Horizonts, 175, 2004.

Corretja i Torrens, M., «La reforma del Estatuto de Autonomía de Cataluña», en Martín Delgado, I.; Ortega Álvarez, L. (coords.), La reforma del Estado autonómico, Cuadernos y Debates, 166, Madrid, Ministerio de la Presidencia-Centro de Estudios Políticos y Constitucionales, 2005.

De Carreras Serra, F., «El proyecto de nuevo Estatuto de Cataluña», en Garrido MAyol, V.; Catalá i Bas, A.; García i Mengual, F. (coords.), Modelo de Estado y Reforma de los Estatutos, Valencia, Fundación Profesor Manuel Broseta, 2007.

De MAdre, M.; ICETA, M. (eds.), El Estatuto de Cataluña: una propuesta para el acuerdo, Barcelona, Fundació Rafael Campalans, 2005.

Dorado, R., «El juego político en torno al Proyecto de Estatuto de Cataluña», Temas para el Debate, 132, 2005.

Fernández Farreres, G., «El Estatuto de Cataluña y la reforma del Estado», Repertorio Aranzadi del Tribunal Constitucional, 18, 2005.

Fradera, J.; Martínez, R., «Constitución y cierra España! El Estatut de Catalunya: mito y realidad», Viento sur: por una izquierda alternativa, 83, 2005.

GABANCHO, P., La batalla de l'Estatut: 1906-2006 cent anys de problema espanyol, Barcelona, Empuréis, 2006. 
García FernÁndeZ, J., «El proyecto de reforma del Estatuto de Cataluña y la Constitución», Temas para el Debate, 132, 2005.

GonzÁlez Casanova, J. A., «Reforma del Estatuto de Cataluña y Estado Federal», Revista de Fomento Social, 241, 2006.

GONZÁlEz SOlER, O. E., «El procedimiento legislativo adecuado para la reforma del Estatuto de Autonomía para Cataluña: Comentario al Auto del Tribunal Constitucional de 15 de marzo de 2006», Repertorio Aranzadi del Tribunal Constitucional, 4, 2006.

Lacometti, M., «La laboriosa approvazione di un nuevo Statuto per la Catalogna», Diritto Pubblico Comparato ed Europeo, 2, 2006.

López Guerra, L., «La función constitucional y el contenido del Estatuto de Autonomía», Estudios sobre la reforma del Estatuto, Institut d’Estudis Autonòmics, 2004.

Madrid Delgado, M.,»Filosofía y problemática del Estatuto de Cataluña», Temas para el Debate, 133, 2005.

Marsal Ferret, M., «Recensió jurisprudencial sobre la reforma de l'Estatut d'Autonomia de Catalunya», Revista Catalana de Dret Públic, 31, 2005.

Mestre Ferret, M. (ed.), Que vénen els catalans: les declaracions més aberrants sobre l'Estatut, Barcelona, Ara LLibres, 2005.

Montilla Martos, J. A., «Apuntes sobre colaboración y participación en el Estado autonómico. A propósito de la propuesta de reforma del Estatuto de Cataluña», Revista d'Estudis Autonòmics i Federals, 1, 2005.

Nebrera, M., «Las zapatillas rojas: a propósito de la reforma del Estatuto de Cataluña», Cuadernos de Pensamiento Político FAES, 7, 2005.

PALlarés, F., «El referéndum del 2006 sobre la reforma del Estatuto de autonomía de Cataluña», en ToRnos MÁs (et al.), Informe sobre las Comunidades Autónomas de 2006, Barcelona, Instituto de Derecho Público, 2007.

Pallarés, F., «2006: el protagonisme polític dels ciutadans. El referéndum de l'Estatut i les eleccions al Parlament», en Montagut, T. (coord.), Societat Catalana, 2007, Barcelona, Associació Catalana de Sociología, 2008.

Pemán GaVín, J. M., «Sobre los límites de las reformas estatutarias: derechos históricos y Estado de las Autonomías. A propósito de la propuesta de nuevo Estatuto aprobado por el Parlamento de Cataluña», Revista General de Derecho Administrativo, 12, 2006.

Peñaranda Ramos, J. L., «Informe sobre la propuesta de reforma de Estatuto de Autonomía de Cataluña», Revista de las Cortes Generales, 64, 2005.

Pérez Calvo, A., Nación, nacionalidades y pueblos en el derecho español: (al bilo de la propuesta de reforma del Estatuto de Autonomía de Cataluña), Madrid, Biblioteca Nueva, 2005.

Pérez Royo, J.; Carrasco Durán, M., «Regulación en el Estatuto de Cataluña de la participación de la Generalidad en las instituciones y políticas estatales», en LóPEZ Guerra, L. (et al.), Estudios sobre la reforma del Estatuto, Barcelona, Institut d'Estudis Autonòmics, 2004.

Pérez Royo, J.; Medina Guerrero, M., «Estudio sobre las disposiciones fiscales en la reforma del Estatuto de Cataluña», en LóPEz GuerRA, L. (et at.), Estudios sobre la reforma del Estatuto, Barcelona, Institut d'Estudis Autonòmics, 2004. 
Pulido QueCedo, M., «De nuevo sobre la tramitación de la reforma de los estatutos de autonomía: la reforma del Estatut», Repertorio Aranzadi del Tribunal Constitucional, 14, 2005.

QuAdRA-SAlCEDO, T., «Después del referéndum de Cataluña. ¡El Estatuto ha muerto! ¡Viva el Estatuto!», Claves de Razón Práctica, 162, 2006.

Redondo, J. L., «Las líneas rojas del Estatut», Transversales: Revista de Opinión Social, Politica y Cultural, 1, 2005-2006.

Ridao i Martin, J., Aixi es va fer l'Estatut: de l'Estatut del Parlament a l'Estatut de la Moncloa, Barcelona, Mediterrània, 2006.

Roca, J. M., «El Estatut en el laberinto», Transversales: Revista de Opinión Social, Politica y Cultural, 1, 2005-2006.

SÁENZ, L. M.; RedOndo, J. L., «La reforma estatutaria en Cataluña», Transversales, Revista de Opinión Social, Política y Cultural, 1, 2005-2006.

SaIZ Arnaiz, A., "Hecho diferencial y reconocimiento nacional en el Estatuto de Autonomía», Estudios sobre la reforma del Estatuto, Institut d'Estudis Autonòmics, 2004.

SÁNCHEZ Llibre, J., Les veritats de l'Estatut: allò que no s'ha publicat al Diari de Sessions, Barcelona, L'esfera dels llibres, 2006.

Santamaría, A., «Referéndum del Estatuto: entre la legalidad y la legitimidad», Temas para el Debate, 140, 2006.

SANTAMARÍA, J.; MARCETO, J., «El referéndum catalán del 18/J. Apoyo, rechazo y abstención», en Elecciones y comportamiento electoral en la España multinivel, Madrid, Centro de Investigaciones Sociológicas, 2006.

SANTAMARÍA, J.; MARCETO, J., «18 J: el referéndum del nuevo estatuto de Cataluña: apoyos, rechazos y abstenciones, Claves de la Razón Práctica, 165, 2006.

Selva Masoliver, M., «La propuesta de reforma del Estatuto de Autonomía de Cataluña», Género, Constitución y Estatuto de Autonomía, Madrid, Instituto Nacional de Administración Pública, 2005.

SOlOzÁbal ECHEVARRía, J. J., «Sobre las reformas estatutarias y la propuesta del Parlamento catalán», en Ruiz-Rico, G. (coord.), La reforma de los Estatutos de Autonomía: actas del IV Congreso Nacional de la Asociación de Constitucionalistas de España, Valencia, Tirant lo Blanch, 2006.

TAjadura TejadA, J., «La reforma del Estatuto de Cataluña: propuestas y límites», en VIVER Pi I SUNYER, C. (et al.), La reforma de los Estatutos de Autonomía: con especial referencia al caso de Cataluña, Madrid, Centro de Estudios Políticos y Constitucionales, 2007.

Vintró i Castells, J., «La tramitación de la reforma del Estatuto de Autonomía de Cataluña en las Cortes Generales: reflexiones sobre algunos elementos del procedimiento parlamentario», en Estudios sobre la Constitución Española: homenaje al profesor Jordi Solé Tura, Madrid, Congreso de los Diputados, 2008.

Viver Pi-SunYer, C., «La reforma del Estatuto de Autonomía de Cataluña», en Guerra, A., (et al.), Reformas territoriales: jornadas de Sigüenza, Madrid, Fundación Pablo Iglesias, 2006.

Viver Pi-Sunyer, C.; Balaguer Callejón, F.; Tajadura Tejada, J., La reforma de los Estatutos de Autonomía: con especial referencia al caso de Cataluña, Madrid, Centro de Estudios Constitucionales, 2005. 
Xiol Ríos, J.A., «Evaluación de los aspectos relacionados con la Administración de justicia en una futura reforma del Estatuto de Autonomía de Cataluña», en Viver Pi-Sunyer, C.; Pérez Royo, J.; Jiménez Asensio, R.; López Guerra, L., y otros, Estudios sobre la reforma del Estatuto, Barcelona, Institut d'Estudis Autonòmics, 2004.

\section{EL NUEVO ESTATUTO DE AUTONOMÍA DE CATALUÑA: ASPECTOS GENERALES}

Aba Catorira, A., «La reforma de los estatutos de autonomía de la Comunidad Valenciana y de Cataluña desde la perspectiva de género, comentario», Artículo 14: una Perspectiva de Género, 22, 2006.

Albertí Rovira, E., «La participació de les comunitats autònomes en institucions de l'Estat en els nous estatuts d'autonomia», Revista Activitat Parlamentària, 15, 2008.

Albertí Rovira, E., «Le noveau statut d'autonomie de la Catalogne», Revue Française d» Administration Publique, 121-122, 2007.

Álvarez Conde, E., Reforma constitucional y reformas estatutarias, Madrid, Iustel, 2007.

Álvarez Junco, J., «España plural, Cataluña plural», Claves de la Razón Práctica, 159, 2006.

Aparicio Pérez, M. A., «L'adequació de l'estructura de l'Estat a la Constituciò (reforma constitucional vs. reforma dels estatuts)», Revista Catalana de Dret Públic, 31, 2008.

Barceló i Serramalera, M.; Vintró i Castells, J., Derecho Público de Cataluña, Barcelona, Atelier, 2008.

Benach i Pascual, E., L'Estatut: una aposta democràtica i moderna, Barcelona, Parlamento de Cataluña, 2006.

Blanco Valdés, R., «El Estatuto catalán: textos y pretextos», Claves de la Razón Práctica, 162, 2006.

Blanco VAldÉs, R., «Lo Statuto catalano: testo e pre-testi», Quaderni Costituzionali, 4, 2006.

Briones Martínez, I., «Relaciones con las entidades religiosas en el Estatuto de Cataluña», en RodríGuez CHACÓN, R. (coord.), Temas candentes de derecho matrimonial y procesal en las relaciones Iglesia-Estado: actas de las XXVI Jornadas de actualidad canónica organizadas por la Asociación Española de Canonistas en Madrid, Madrid, Dykinson, 2007.

Caja, F., «Estatuto de Cataluña y soberanía española», Noticiero de las Ideas, 26, 2006.

Capo Giol, J.; Marcet Morera, J., «El Parlament de Catalunya en clau de futur», Revista d'Estudis Autonòmics i Federals, 5, 2007.

Carreras, F., «El Estatuto de Cataluña, aventura irresponsable», Noticiero de las Ideas, 27, 2006. 
Carrillo López, M., «El nuevo Estatuto de Autonomía de Cataluña de 2006, en el marco de las reformas estatutarias en España», Revista de Derecho, 1, 2008.

Carrillo, M. (dir.); López Bofill, H.; Torres, A., L'Estatut d'Automia de Catalunya de 2006, Barcelona, Textos jurìdics, Institut d'Estudis Autonòmics, 2006.

Corretja i Torrens, M., «L'Estatut d'Autonomia de 2006. Aspectos territorials», Anuari Territorial 2006, Societat Catalana d'Ordenació del Territori, Institut d'Estudis Catalans, 2007.

Cruz Villalón, P., «La reforma del Estado de las Autonomías», Revista d'Estudis Autonòmics i Federals, 2, 2006.

DurANTI, G., «Asimetría e modernizzazione del federalismo in Europa: il caso della reforma dello statuto catalano», Rassegna Parlamentare, 1, 2008.

Elvira Ayuso, L., «Las Comunidades Autónomas en el Consejo de la Unión Europea: la representación de Cataluña», Revista d'Estudis Autonòmics i Federals, 8, 2009.

EsPADA GARCíA, A., Informe sobre la decadencia de Cataluña reflejada en su Estatuto, Madrid, Espasa Calpe, 2006.

FERnÁndez Rodríguez, T.R., «De la reforma de los Estatutos a la reforma de la Constitución», Foro: Revista de Ciencias Jurídicas y Sociales. Nueva época, 5, 2007.

Ferreres Comella, V., «A propósito del nuevo Estatuto de Autonomía de Cataluña», Noticiario de las Ideas, 29, 2007.

Fradera, J., «Catalunya ante un estatuto descafeinado y un nuevo movimiento soberanista», Viento sur: por una izquierda alternativa, 86, 2006.

García-Capelo Villalva, F., «Del nou Estatut a la España futura», Noticiario de las Ideas, 28, 2006.

García-CAPelo Villalva, F., El Estatuto de la discordia: análisis y comentarios para profanos en torno al texto más polémico de la democracia, Vitoria, Fundación Papeles de Ermua, 2007

GonZÁlez Casanova, J. A., «Cataluña en la construcción del Estado español», Cuadernos Constitucionales de la Cátedra Fadrique Furió Ceriol, 54-55, 2006.

Gordillo, L. I., «A vueltas con los privilegios parlamentarios: la regulación de la inmunidad en los ordenamientos europeos y la introducción del suplicatorio en el artículo 57 de la propuesta de reforma del Estatuto de Autonomía de Cataluña», en Ruiz-Rico, G. (coord.), La reforma de los Estatutos de Autonomía: actas del IV Congreso Nacional de la Asociación de Constitucionalistas de España, Valencia, Tirant lo Blanch, 2006.

Homs i Molist, F., Catalunya a judici, Barcelona, Ara Llibres, 2008.

LÓPEZ De Lerma i LÓPEZ, J., «Relaciones Generalidad-Estado en el nuevo Estatuto de Autonomía de Cataluña», La Ley: Revista Jurídica Española de doctrina, Jurispruencia y Bibliografía, 1, 2007.

López GarCía, C., «Cinco cuestiones fundamentales en el nuevo Estatuto de Autonomía para Cataluña, aprobado por Ley Orgánica 6/2006», Consultor de los ayuntamientos y de los juzgados: Revista técnica especializada en administración local y justicia municipal, 21, 2009.

López Medel, J., «El Estatuto de Cataluña como instrumento jurídico», Razón Española: Revista Bimestral de Pensamiento, 135, 2006. 
López Medel, J., El Estatuto de Cataluña como instrumento jurídico: una meditación sobre España, Madrid, Fragua, 2006.

Merino Pacheco, F. J.; Puente GonzÁlez, CH., «Estatuto catalán, una visión crítica desde la izquierda», El Viejo Topo, 216, 2006.

Mir Puigpelat, O., «La Comissió Jurídica Asesora como a garant de l'autonomia», Revista Catalana de Dret Públic, 39, 2009.

Monreal Ferrer, A. L., «La reforma del Estatuto de Autonomía de Cataluña y la Constitución», en Estudios sobre la Constitución Española: homenaje al profesor Jordi Solé Tura, Madrid, Congreso de los Diputados, 2008.

Monreal Ferrer, A. L., «La reforma del Estatuto de Autonomía de Cataluña», en GArrido Mayol, V.; Catalá i Bas, A.; García i Mengual, F. (coords.), Modelo de Estado y Reforma de los Estatutos, Valencia, Fundación profesor Manuel Broseta, 2007.

Morales Moreno, A., «Aspectos estilístics en la redacció de textos administratius: anàlisi comparativa dels estatuts d’autonomia de Catalunya de 1979 i de 2006», Revista de Llengua i Dret, 49, 2008.

Pérez Francesch, J. L., «El Estado de las Autonomías a debate: una reflexión desde Cataluña», Cuadernos Constitucionales de la Cátedra Fadrique Furió Ceriol, 54-55, 2006.

Pérez TreviÑo, J. L., «El Estatut y los abusos de dignidad», Cuadernos de Derecho Público, 32, 2007.

Poggeschi, G., «La definitiva aprovazione del nuovo Statuto di autonomia della Catalogna. Un passo in avanti verso una Maggiore asimetría dell'Estado autonómico?», Diritto Pubblico Comparato ed Europeo, 3, 2006.

Puig, V., «Un estatut para la disidencia», Revista de Política, Cultura y Arte, 106, 2006.

Pulido Quecedo, M., «Los preámbulos de los estatutos de autonomía», Repertorio Aranzadi del Tribunal Constitucional, 15, 2006.

Ridao i Martin, J., Curs de Dret Públic de Catalunya. Comentari a l'Estatut, Barcelona, Ariel-Escola d'Administració Pública, 2007.

RIDAO i MARTIN, J., «Les bases de l'autonomia politica de Catalunya fixades en el nou Estatut», Revista Jurídica de Catalunya, 4, 2007.

Roig MolÉs, E., «La regulació de les relacions de la Generalitat amb l'Estat en el nou Estatut d'autonomia de Catalunya», Revista d'Activitat Parlamentària, 15, 2008.

RugGIU, I., «Il nuovo Statuto Catalano», Le Regioni: Rivista Bimestrale di Documentazione e Giurisprudenza dell'Istituto di Studi Giuridici Regionali, 2, 2007.

SÁENZ, L. M., «Estatut: un buen punto de partida», Transversales: Revista de Opinión Social, Politica y Cultural, 1, 2005-2006.

SALVADOR, M., «Innovació institucional i capacitatas de gestió de l'administració autonómica: el cas de la Generalitat de Catalunya», Revista d'Estudis Autonòmics i Federals, 7, 2008.

SAntos, L.; Bonet, L.; Fuentes, D.; ICETA, M., El nou Estatut. Comentari a peu d obra, Barcelona, Fundació Rafael Campanals, 2006.

SANZ PÉrez, A. L., La reforma de los Estatutos de Autonomía: (con especial referencia a los estatutos de autonomía de Cataluña y de la Comunidad Valenciana), Cizur Menor, Aranzadi, 2006.

SAURA, J., Un nou Estatut de Catalunya per a una Espanya Federal, Barcelona, Generalitat de Catalunya, 2006. 
SOSA WAGNER, F.; SOSA MAYOR, I., El Estado fragmentado: modelo austro-búngaro y brote de naciones en España, Madrid, Trotta, 2006.

Soubirats Corujo, B., «L'Estatut: una anàlisi tècnica», en Llibre de l'any: 2005, Barcelona, Edicions 62, 2006.

Tornos Mas, J., Los Estatutos de Autonomía de Cataluña, Iustel, Institut d'Estudis Autonòmics, 2007.

Tremosa Balcells, R., Estatut de Catalunya. Veritats contra mentides: guia de defensa del nou Estatut i de valoració del nou modelo de finançament, València, Eliseu Climent, 2006.

Velarde Fuertes, J., «Sobre el nuevo Estatuto de Cataluña», Razón Española: Revista Bimestral de Pensamiento, 139, 2006.

Vintró I CASTElls, J.; PADRós, X., L’Estatut d'autonomia de Catalunya: trests generals, Barcelona, Institut de Dret Públic, 2006.

VIVER PI-SunYeR, C., «La reforma dello statuto della comunità autonoma di Catalogna: principali novità e problema di costituzionalità insorti», en D`Atena, A. (ed.), I cantieri del federalismo in Europa, Milano, Giuffré, 2008.

Viver Pi-SunYer, C., «La reforma dello Statuto della Comunità Autonoma di Catalogna: principali novità e problema di costituzionalità», Revista di Diritto e Societá, 3, 2008.

Viver Pi-SunYer, C., «L'Estatut del 2006», Activitat Parlamentària, 10, 2006.

Viver Pi-SunYer, C., «El Estatuto de Cataluña en el marco de la Constitución», en Pau i Vall, F. (coord.), Las Reformas estatutarias y la articulación territorial del Estado, XIV Jornadas de la Asociación Española de Letrados de Parlamentos, Madrid, Tecnos, 2008.

\section{COMPETENCIAS}

\section{IV.1. LAS COMPETENCIAS EN EL PROCESO DE REFORMA ESTATUTARIA}

Aguilar Fontalba, J., «Poder Judicial y administración de justicia en la propuesta del nuevo Estatuto para Cataluña», Repertorio Aranzadi del Tribunal Constitucional, 18, 2005.

Albertí Rovira, E., «El blindatge de les competències i la reforma estatutària», Revista Catalana de Dret Públic, 31, 2005.

Balaguer CALlejón, F., Las reformas estatutarias desde la perspectiva de la ordenación competencial: un análisis de las líneas generales del título $V$ de la propuesta de reforma del Estatuto de Autonomía de Cataluña, Madrid, Centro de Nuevas Estrategias de Gobernanza Pública, 2005.

BARnés VÁZQueZ, J., «Legislación básica y Estatuto de Autonomía», en Estudios sobre la reforma del Estatuto, Barcelona, Institut d'Estudis Autonòmics, 2004.

Biglino Campos, P., «Reforma de la Constitución, reforma de los Estatutos de Autonomía y configuración constitucional del orden de competencias», Revista de las Cortes Generales, 65, 2005.

Borrell Mestre, J., «Justicia y Comunidades Autónomas. Las modificaciones que se tramitan en el Congreso de los Diputados. Especial referencia al proyecto de re- 
forma del Estatuto de Autonomía en Cataluña», Revista Española de la Función Consultiva, 4, 2005.

Corretja Torrens, M.; Viver Pi-Sunyer, C., «La reforma de l'Estatut d'Autonomia i les competències de la Generalitat», Revista Activitat Parlamentària, 7, 2005

Desdentado Bonete, A., «La Seguridad Social y la propuesta de Estatuto de Cataluña: algunos puntos de reflexión», Diario La Ley, 6402, 18 de enero de 2006.

Gerpe landín, M.; Cabellos Espiérrez, M. A.; Fernández de los Frutos, M., «El Tribunal Superior de Justicia de Cataluña. Una propuesta de reforma de sus competencias», Revista Jurídica de Catalunya, 3, 2005.

Jiménez AsEnsio, R., «Reforma del Estatuto de Cataluña y ampliación de competencias», Revista Vasca de Administración Pública, 70, 2004.

JimÉNEZ AsENSIO, R., «Competencias ejecutivas y administración única», Estudios sobre la reforma del Estatuto, Institut d'Estudis Autonòmics, 2004.

Leguina Villa, J., «La transferencia o la delegación de competencias estatales por medio del Estatuto de Autonomía», en Estudios sobre la reforma del Estatuto, Barcelona, Institut d'Estudis Autonòmics, 2004.

PÉREZ TREMPS, P., «La acción exterior y la participación europea ante una posible reforma del Estatuto de Cataluña», en LóPEz Guerra, L. (et al.), Estudios sobre la reforma del Estatuto, Barcelona, Institut d'Estudis Autonòmics, 2004.

Prados Prados, S., «El deporte en la propuesta de reforma del Estatuto de Autonomía de Cataluña», Revista Andaluza de Derecho del Deporte, 1, 2006.

Serra Cristobal, R., «El proceso de adecuación de la justicia al Estado Autonómico: (las proposiciones de reforma de los estatutos vasco, catalán y valenciano en materia de justicia)», en RUIZ-RICO, G. (coord.), La reforma de los Estatutos de Autonomía: actas del IV Congreso Nacional de la Asociación de Constitucionalistas de España, Valencia, Tirant lo Blanch, 2006.

SuÁrez Corujo, B., «Los artículos 165 y 166 de la Propuesta de Reforma del Estatuto de Autonomía de Cataluña: Configuración de la Seguridad Social en el Estado autonómico», Justicia Laboral: Revista de Derecho del Trabajo y de la Seguridad Social, 26, 2006.

SuÁrez Corujo, B., «La seguridad social en la propuesta de reforma del Estatuto de Autonomía de Cataluña», Revista Jurídica de la Universidad Autónoma de Madrid, 13, 2005.

Xiol Ríos, J. A., «Evaluación de los aspectos relacionados con la Administración de justicia en una futura reforma del Estatuto de Autonomía de Cataluña», en LóPEZ GuERra, L. (et al.), Estudios sobre la reforma del Estatuto, Barcelona, Institut d'Estudis Autonòmics, 2004.

\section{IV.2. LA DISTRIBUCIÓN DE COMPETENCIAS EN EL NUEVO ESTATUTO DE AUTONOMÍA}

AAVV., La distribució de competències en el nou Estatut, Barcelona, Institut d’Estudis Autonòmics, 2007. 
Armengol i Ferrer, F., «Els acords d'acció exterior de la Generalitat en el nou marc estatutari», Revista d'Estudis Autonòmics i Federals, 6, 2008.

Aymerich, R.; COMA, J., «Estatut i educació, entre les competències i els drets», Guix, Elements d'Acció Educativa, 333, 2007.

Barceló i Serramalera, M., «La delimitació del concepte de bases a l'Estatut d'autonomia de Catalunya», en Viver PI-SunYer, C. (et al.), La distribució de competències en el nou Estatut, Barcelona, Institut d'Estudis Auutonòmics, 2007.

Bernardí GIL, X., «Competencias ejecutivas y potestad reglamentaria», Revista d'Estudis Autonòmics i Federals, 6, 2008.

BLANCO VALDÉs, R., «Blindaje competencial e indefensión constitucional», Claves de la Razón Práctica, 176, 2007.

Bosch CAPDevila, E., «La distribución de competencias en materia de legislación civil. De la Constitución española de 1931 al Estatuto de Cataluña de 2006», Revista Crítica de Derecho Inmobiliario, 83, 2007.

CArceller Fernández, A., «El urbanismo y el medio ambiente en el nuevo Estatuto de Autonomía de Cataluña», Revista de Derecho Urbanístico y Medio Ambiente, 233, 2007.

Cavas Martínez, F., «La protección social en los nuevos estatutos de autonomía», Aranzadi Social, 6, 2007.

Corretja Torrens, M., «La participació de la Generalitat en l'exercici de competències estatals a l'Estatut de 2006: les infraestructuras del transport», Revista d'Estudis Autonòmics $i$ Federals, 5, 2007.

CORretja TORRens, M., «El nou disseny competencial en matèria de funció pública i règim jurídic de les administracions públiques catalanes», La distribució de competències en el nou Estatut, Col.lecció IEA, Institut d'Estudis Autonòmics, 52, 2007.

De Palma Del Teso, A., «Las competencias de la Generalitat de Cataluña en materia de protección pública de menores», Revista d'Estudis Autonòmics i Federals, 5, 2007.

De SICART, S., «Las dudas sobre Seguridad privada que suscita el Estatuto de Cataluña», Seguritecnia: Revista decana independiente de Seguridad, 355, 2009.

Embid Irujo, A. (dir.), Agua y territorio: (consideración especial de la Reforma de los estatutos de autonomía), Cizur Menor, Civitas, 2007.

FARré, R., «L'Estatut d'autonomia de Catalunya i la Llei orgànica d'Educació: un anàlisi competencial», Revista del Col.legi Oficial de Doctors $i$ Llicenciats en Filosofia i Lletres i en Ciències, 127, 2007.

Gala DurÁN, C., «L'exercici de competències autonòmiques en matèria de Seguretat Social», Revista d'Estudis Autonòmics i Federals, 3, 2006.

García, C.; Morgades, S.; Rodrigo, A., «Las relaciones exteriores de la Generalitat en el Estatuto de autonomía de Cataluña de 2006», Anuario de Derecho Internacional, 22, 2006.

García i Segura, C.; Vaquer i Fanés, J., «La acción exterior de la Generalitat de Cataluña ante la reforma del Estatuto de Autonomía», en GARCíA PÉreZ, R., La acción exterior de las Comunidades autónomas en las reformas estatutarias, Madrid, Tecnos, 2009.

GArcía Torres, J., «La tipología de las competencias en la reforma del Estatuto de Autonomía de Cataluña», Anales de la Academia Matritense del Notariado, 47, 2009. 
GraU i Corominas, E., «Les competències en matèria d'universitats i en matèria de recerca, desenvolupament i innovació tecnològica al l'Estatut d'autonomia de Catalunya de 2006», Coneixement i Societat: Revista d'Universitats, Recerca i Societat de la Informació, 12, 2006.

LALANDA, C., «Las competencias sobre el juego a raíz de la reforma del Estatuto de $\mathrm{Au}-$ tonomía de Cataluña de 2006», Revista Jurídica de Deporte y Entretenimiento: Deportes, Juegos de Azar, Entretenimiento y Música, 17, 2006.

Martí Torres, R.; Grau Coromines, E., «El regim jurídic del personal docent i investigador contractat, regulat a la Llei 1/2003, de 19 de Febrer, d'Uiversitat de Catalunya, en el context del nou Estatut d'autonomia de Catalunya i de la modificació de la Llei orgànica d'Universitatis», Coneixement i Societat. Revista d'Universitats, Recerca y Societat de la Informació, 13, 2007.

Molina Navarrete, C., La dimensión socio-laboral de los nuevos estatutos de autonomía: un estudio particular de los estatutos andaluz y catalán, Sevilla, Mergablum, 2007.

PAdrós CASTILLÓN, X., «La llei de contractes del sector públic i les competències de la Generalitat de Catalunya sobre contratació: possibilitats de desenvolupament», Revista d'Estudis Autonòmics i Federals, 6, 2008.

PADRós ReIG, C., La competencia autonòmica ejecutiva sobre el règim administratiu de les activitats d'inspecció tècnica, Barcelona, Institut d'Estudis Autonòmics, 2007.

Palomares Amat, M., «Las relaciones entre la Generalitat de Cataluña y la UE en el Estatuto de Cataluña del 2006», Revista Electrónica de Estudios Internacionales, 13, 2007.

Pierre-VANtol, B., «Autonomie politique et réforme statutaire en Espagne: regards juridiques sur le blindage des compétences autonomes dans le nouveau statut de la Catalogna», Revue Française de Droit Constitutionnel, 81, 2010.

PONCE SOlÉ, J., «La competencia en materia de vivienda a la luz del nuevo estatuto de autonomía de Cataluña y de la ley catalana 18/2007, de 28 de diciembre, del derecho a la vivienda», en PONCE Solé, J., SiBINA TOMÁs, D. (coords.), El derecho de la vivienda en el siglo XXI: sus relaciones con la ordenación del territorio y el urbanismo: con un análisis específico de la Ley catalana 18/2007, de 28 de diciembre, del derecho a la vivienda, en su contexto español, europeo e internacional, Madrid, Marcial Pons, 2008.

Pons Refols, X.; SAgarRa Trías, E., La acción exterior de la Generalitat en el nuevo Estatuto de Autonomía de Cataluña, Barcelona, Universidad de Barcelona, 2006.

Punzón Moraleda, J.; SÁnchez Rodríguez, F., «El Estatuto de Autonomía de Cataluña y las competencias deportivas», Revista Jurídica del Deporte y entretenimiento: deportes, juegos de azar, entretenimiento y música, 23, 2008.

Riu FortunY, R., «La regulació de l'abast territorial i els efectes de les competències», en AAVV., La distribució de competències en el nou Estatut, Barcelona, Institut d'Estudis Autonòmics, 2007.

SÁNCHEZ CAMACHO, R., «Las competències sobre el agua en las reformas estatutarias», Aletheia, 2, 2007.

Santolaya Machetti, P., «Extranjería y nuevos estatutos de autonomía», Revista d'Estudis Autonòmics i Federals, 4, 2007.

SAntolaya MachetTi, P., «Las competencias autonómicas en extranjería en los proyectos de reforma de los estatutos valenciano y catalán», en RUIZ-RICO, G. (coord.), La 
reforma de los Estatutos de Autonomía: actas del IV Congreso Nacional de la Asociación de Constitucionalistas de España, Valencia, Tirant lo Blanch, 2006.

ToRnOs MAS, J., «La nueva configuración de las competencias compartidas en el Estatuto de Autonomía: algunos problemas que plantea su aplicación», Revista General de Derecho Constitucional, 5, 2008.

Vilá i MANCEBO, A., «La llei de promoció de l'autonomia personal i atenció a personas en situació de dependencia i el nou Estatut d'autonomia de Catalunya», Revista de Treball Social, 182, 2007.

Viver Pi-Sunyer, C., «Les competències de la Generalitat a l'Estatut 2006: Objectius, tècniques emprades, criterios d interpretació i comparació amb els altres estatuts reformats», en AAVV., La distribució de competències en el nou Estatut, Barcelona, Institut d'Estudis Autonòmics, 2007.

YZquierdo Tolsada, M., «Nuevos estatutos de autonomía y legiferación civil», Derecho Privado y Constitución, 21, 2007.

Yzquierdo Tolsada, M., «De como Ambrosio se quedó sin coche (o el derecho civil ante el Estatut)», La Tribunal del Derecho, 15-30 de abril, 2006.

\section{FINANCIACIÓN}

Arias Abellán, M. D., «La ordenación jurídica de los recursos financieros en el Estatuto de Autonomía de Catalunya», Revista d'Estudis Autonòmics i Federals, 6, 2008.

Bosch i RocA, N., «El model de finançament autonòmic del projecte de reforma de l'Estatut de Catalunya», Revista Catalana de Dret Públic, 32, 2006.

Bosch i RocA, N., «El finançament en el nou Estatut d'autonomia de Catalunya: resol els problemas de l'actual model de finançament de les comunitats autònomes?», en Memoria econòmica de Catalunya, Barcelona, Cambres Oficials de Comerç, Indústria i Navegació de Catalunya, 2006.

ESCRIBANO LÓPEZ, F., «La reforma de la financiación autonómica en el marco de los nuevos Estatutos», Revista Andaluza de Administración Pública, 62, 2006.

Ferreiro Lapatza, J. J., «El sistema de financiación autonómica de Cataluña: Estatuto y Constitución», Revista Catalana de Dret Públic, 32, 2006.

García NovoA, C., «El sistema de financiación en la reforma del Estatuto catalán. ¿Es compatible con el orden constitucional?», Revista Catalana de Dret Públic, 32, 2006.

Girón Guerrero, E., «La incidencia de las reformas de los Estatutos de Autonomía en la financiación autonómica», Revista Española de Derecho Constitucional, 80, 2007.

LÓPEZ LABORDA, J., «Las Haciendas autonómicas en 2005: la financiación del gasto sanitario y la propuesta de reforma del Estatut», en Informe Comunidades Autónomas: 2005, Barcelona, Instituto de Derecho Público, 2006.

PAGÈs i Galtés, J., Financiación autonómica, local y sectorial en el nuevo Estatuto de Catalunya, Madrid, Marcial Pons, 2007.

PAGÉs I GALtés, J., «El sistema de financiación autonómica en el Estatuto catalán de 2006», en La financiación autonómica en los estatutos de autonomía, Madrid, Marcial Pons, 2008. 
Pérez Royo, F.; Medina Guerrero, M., «Estudio sobre las disposiciones fiscales en la reforma del Estatuto de Cataluña», en PÉRez Royo, J.; Jiménez Asensio, R.; LóPEZ GuERrA, L., y otros, Estudios sobre la reforma del Estatuto, Barcelona, Institut d'Estudis Autonòmics, 2004.

Quintana Ferrer, E., «La financiación de la Generalitat en el nuevo Estatuto de $\mathrm{Au}$ tonomía de Catalunya», Nueva Fiscalidad, 6, 2007.

Rodríguez Bereijo, A., «Reflexión final: la financiación autonómica y el Estatuto de Cataluña», en Descentralización política y descentralización fiscal: la experiencia española, Repertorio Aranzadi del Tribunal Constitucional, 20, 2006.

SÁNCHEZ PeDROCHE, J. A., «La financiación autonómica o la reforma del Estatuto de Autonomía Catalán», Revista Valenciana d'Estudis Autonòmics, 45-46, 2004.

Sevilla Segura, J. V., «La financiación autonómica después del nuevo Estatuto de Cataluña», en Ferraro García, F. J. (coord.), Un balance del estado de las autonomías, Almería, Cajamar Caja Rural, 2006.

Sevilla Segura, J. V., «La propuesta catalana de financiación autonómica», Claves de la Razón Práctica, 154, 2005.

Zabalza, A., «La financiación autonómica en el Estatuto de Cataluña», Hacienda Pública Española, 181, 2007.

\section{DERECHOS ESTATUTARIOS}

Albertí Rovira, E., «El nuevo Consejo de Garantías Estatutarias del Estatuto de Autonomía de Cataluña como instrumento de garantía de los derechos», Revista Vasca de Administración Pública, 82, 2008.

Aparicio Wilhelmi, M.; Jaria I Manzano, J.; Pisarello Prados, G., «Los derechos y principios del ámbito civil y social en el Estatuto de Autonomía de Cataluña», en Aparicio Pérez, M. M.; Castellá I Andreu, J. M.; Expósito, E. (coords.), Derechos $y$ principios rectores en los estatutos de autonomía, Atelier, Barcelona, 2008.

Aparicio Wilhelmi, M.; Pisarello Prados, G., El reconocimiento de derechos, deberes y principios en los Estatutos de Autonomía: ¿Hacia una comprensión multinivel o en red de la protección de los derechos?, Barcelona, Institut d'Estudis Autonòmics, 2007.

Balaguer Callejón, M. L., «Reformas estatutarias y reconocimiento de derechos», Revista General de Derecho Constitucional, 3, 2007.

BARCeló i SeRramalera, M., «Els drets lingüìstics com a drets públics estatutaris», Revista de Llengua i Dret, 47, 2007.

BARRAL Viñals, I., «Los derechos de los consumidores y los límites del marco competencial en el Estatuto de Cataluña de 2006», en CASTEllà I ANDreu, J. M.; GramMOND, S. (coords.), Los derechos de los consumidores y los límites del marco competencial en el Estatuto de Cataluña, Barcelona, Atelier, 2010.

CaAmaño Domínguez, F., «Sí, pueden (declaraciones de derechos y estatutos de autonomía)», Revista Española de Derecho Constitucional, 79, 2007.

Carrillo LóPez, M., «Los derechos, un contenido constitucional de los Estatutos de Autonomía», Revista Española de Derecho Constitucional, 80, 2007.

Castellá Andreu, J. M. (coord.); Expósito Gómez, E.; Martín Núñez, E., Els drets da- 
vant l'Administració $i$ les seves garanties en l'Estatut d'Autonomia de Catalunya, Col.lecció Estudis, 28, Barcelona, Escola d'Administració Pública de Catalunya, 2007.

DíEZ-PicAzo, L. M., «De nuevo sobre las declaraciones estatutarias de derechos: respuesta a Francisco Caamaño», Revista Española de Derecho Constitucional, 81, 2007.

Díez-Picazo, L. M., «¿Pueden los Estatutos de Autonomía declarar derechos, deberes y principios?, Revista Española de Derecho Constitucional, 78, 2007.

EnéRIz OlaeCheA, F. J., «La regionalización de los derechos de los ciudadanos en el ordenamiento español: el nuevo Estatuto de Autonomía de Cataluña», en Oliver Sola, M. C., Zoco Zabala, C., Temas actuales de Derecho, Universidad Pública de Navarra, 2007.

EXPósito, E.; CASTELlÁ i ANDREU, J. M., «Los derechos políticos y ante la administración en el Estatuto de Autonomía de Cataluña», en Aparicio Pérez, M. A.; CasTEllá i ANDreu, J. M.; ExPósito, E. (coords.), Derechos y principios rectores en los estatutos de autonomía, Atelier, Barcelona, 2008.

Expósito, E.; Martín Nuñez, E.; Castellà Andreu, J. M. (coord.), Els drets davant l'administració $i$ les seves garanties en l'Estatut d'autonomia de Catalunya, Barcelona, Escola d'Administració Pública de Catalunya, 2007.

Ferreres Comella, V.; Biglino Campos, P.; Carrillo, M., Derechos, deberes y principios en el nuevo Estatuto de Autonomía de Cataluña, Madrid, Centro de Estudios Políticos y Constitucionales, 2006.

GARCía Torres, J., «Los derechos estatutarios en la propuesta catalana de reforma», en El Estado autonómico: actas de las XI Jornadas de la Asociación de Letrados del Tribunal Constitucional, Madrid, Centro de Estudios Constitucionales-Tribunal Constitucional, 2006.

Martín Nuñez, E.; Castellá I Andreu, J. M., «Las garantías de los derechos en el Estatuto de Autonomía de Cataluña», en Aparicio Pérez, M. A.; Castellá i ANDreu, J. M.; Expósito, E. (coords.), Derechos y principios rectores en los estatutos de autonomía, Atelier, Barcelona, 2008.

Nieva FenOll, J., «Los mecanismos de tutela de los derechos estatutarios», en HOFMANN, R., Estado compuesto y derechos de los ciudadanos, Barcelona, Institut d'Estudis Autonòmics, 2007.

Rey Martínez, F., «El concepto de derechos históricos en la reforma de los estatutos de autonomía», Cuadernos de Alzate, 34, 2006.

\section{CONTROL DE CONSTITUCIONALIDAD}

VII.1. El CONTROL DE CONSTITUCIONALIDAD DE LOS ESTATUtos DE AUTONOMÍA Y LOS PROBLEMAS DE CONSTITUCIONALIDAD DEL ESTATUT

Aparicio Pérez, M. A., «Protecció de l'autogovern i control d'estaturietat: El Consell de Garanties Estatutàries», Revista Catalana de Dret Pùblic, 39, 2009. 
CONTE, G., «El control de estatutoriedad de las leyes regionales y los órganos de garantía: ¿hacia un pseudo modelo de justicia constitucional?», Revista Catalana de Dret Públic, 39, 2009.

Cruz Villalón, P., «La dificultad del Tribunal Constitucional como garante de la autonomía territorial», Revista Catalana de Dret Públic, 39, 2009.

García Fontanet, A., "Quién debe decidir como nos organizamos: el papel del Tribunal Constitucional ante el Estatuto catalán», El Ciervo, 673, 2007.

García i Mengual, F., «La constitucionalidad de la propuesta de reforma del Estatuto de Autonomía de Cataluña: consideraciones del Consell Consultiu de la Generalitat de Catalunya», Revista Española de la Función Consultiva, 4, 2005.

Herrero, R., «La posición del Tribunal Constitucional y el Estatuto de Autonomía de Cataluña», Temas para el Debate, 182, 2010.

Lamarca i Marquès, A.; CASAdo i Pérez, V., «Comparativa entre les reformes dels estatuts d'autonomia de Catalunya i Andalusia: articles impugnats davant el Tribunal Constitucional», InDret: Revista per a l'Analisi del Dret, 391, 2006.

SOlOzÁBAl ECheVArRíA, J. J., «El Estatuto de Cataluña ante el Tribunal Constitucional», Teoría y Realidad Constitucional, 24, 2009.

TAjadura Tejada, J., «Reformas estatutarias y control previo de constitucionalidad», Revista Española de Derecho Administrativo, 132, 2006.

\section{VII.2. LA SENTENCIA DEL Tribunal CONSTITUCiONAL SOBRE El Estatut}

AAVV., «Informe sobre l'STC que resol el recurs d'inconstitucionalitat presentat per 50 diputats i senadors del Partit Popular contra l'Estatut d'Autonomia de Catalunya», Activitat Parlamentaria, Especial sentencia del Tribunal Constitucional sobre l'Estatut d'Autonomia de Catalunya, 2010.

AAVV., «Valoración general de la sentencia», Revista Catalana de Dret Públic, Especial sentencia sobre el Estatut, 2010.

AAVV., «El Tribunal Constitucional ante el Estatuto», Revista Catalana de Dret Públic, Especial sentencia sobre el Estatut, 2010.

AAVV., «El Estatuto como norma y su función constitucional», Revista Catalana de Dret Públic, Especial sentencia sobre el Estatut, 2010.

AAVV., «Cataluña como nación y los símbolos nacionales», Revista Catalana de Dret Públic, Especial sentencia sobre el Estatut, 2010.

AAVV., «Los derechos históricos», Revista Catalana de Dret Públic, Especial sentencia sobre el Estatut, 2010.

AAVV., «La lengua», Revista Catalana de Dret Públic, Especial sentencia sobre el Estatut, 2010 .

AAVV., «Derechos y garantías jurisdiccionales», Revista Catalana de Dret Públic, Especial sentencia sobre el Estatut, 2010.

AAVV., «Instituciones», Revista Catalana de Dret Públic, Especial sentencia sobre el Estatut, 2010.

AAVV., «El poder judicial», Revista Catalana de Dret Públic, Especial sentencia sobre el Estatut, 2010. 
AAVV., «Regimen local», Revista Catalana de Dret Públic, Especial sentencia sobre el Estatut, 2010.

AAVV., «Las competencias», Revista Catalana de Dret Públic, Especial sentencia sobre el Estatut, 2010.

AAVV., «Las relaciones institucionales de la Generalidad», Revista Catalana de Dret Públic, Especial sentencia sobre el Estatut, 2010.

AAVV., «La financiación», Revista Catalana de Dret Públic, Especial sentencia sobre el Estatut, 2010.

AAVV., «La reforma del Estatuto», Revista Catalana de Dret Públic, Especial sentencia sobre el Estatut, 2010.

AAVV., «Nuevos horizontes», Revista Catalana de Dret Públic, Especial sentencia sobre el Estatut, 2010.

Albertí Rovira, E., «El Estado de las Autonomías después de la Sentencia del Tribunal Constitucional sobre el Estatuto de Cataluña», El Cronista del Estado Social y Democrático de Derecho, 15, 2010.

Balaguer Callejón, F., «Las cuestiones institucionales en la STC 31/2010, de 28 de junio», El Cronista del Estado Social y Democrático de Derecho, 15, 2010.

BAYONA, A., «La sentencia del Tribunal Constitucional sobre l'Estatut d'Autonomia de Catalunya», Activitat Parlamentaria, Especial sentencia del Tribunal Constitucional sobre l'Estatut d'Autonomia de Catalunya, 2010.

BlanCo VAldÉs, R., «El Estatuto catalán y la sentencia de nunca acabar», Claves de la Razón Práctica, 205, 2010.

Carrillo, M., «Después de la sentencia, un Estatuto desactivado», El Cronista del Estado Social y Democrático de Derecho, 15, 2010.

Castellá Andreu, J. M., «La sentencia del Tribunal Constitucional 31/2010, sobre el Estatuto de Autonomía de Cataluña y su significado para el futuro del Estado Autonómico», Documentos de la Fundación Ciudadanía y Valores, septiembre 2010, www.funciva.org.

De Carreras Serra, F., «Cataluña tras la sentencia del Estatuto», Letras Libres, 108, 2010.

De Carreras Serra, F., «¿Es constitucional el Estatuto de Cataluña?, Claves de la Razón Práctica, 206, 2010.

De Esteban, J., «Reflexiones en torno al voto particular de Javier Delgado», El Cronista del Estado Social y Democrático de Derecho, 15, 2010.

De la Quadra-Salcedo Janini, T., «El modelo competencial en la STC 31/2010, de 28 de junio», El Cronista del Estado Social y Democrático de Derecho, 15, 2010.

Del Pozo, A. B., «Estatuto de Cataluña: alcance e interpretaciones de la Sentencia del Constitucional», Iuris: Actualidad y práctica del Derecho, 152, 2010.

Elías MéNDEZ, C., "Aproximación a la sentencia del Tribunal Constitucional sobre el Estatuto de Autonomía de Cataluña: nación, lengua, derechos y competencias», Revista General de Derecho Constitucional, 10, 2010.

Fernández FARreres, G., «Las competencias de Cataluña tras la sentencia del Tribunal Constitucional sobre el Estatut», El Cronista del Estado Social y Democrático de Derecho, 15, 2010. 
GALOFRÉ, J., «Comentari sobre la STC 31/2010 en el recurs sobre l'Estatut d'Autonomia de Catalunya», Activitat Parlamentaria, Especial sentencia del Tribunal Constitucional sobre l'Estatut d'Autonomia de Catalunya, 2010.

García-Moncó, A., «Paisaje después de una sentencia: la penúltima reforma de la financiación autonómica», El Cronista del Estado Social y Democrático de Derecho, 15, 2010 .

García Roca, J., «De las competencias en el Estatuto de Cataluña según la STC 31/2010, de 28 de junio: una primera lectura integradora», El Cronista del Estado Social y Democrático de Derecho, 15, 2010.

MuÑoz MaChado, S., «Dentro de los términos de la presente Constitución», El Cronista del Estado Social y Democrático de Derecho, 15, 2010.

Punset BlanCO, R., «El Estatuto de Cataluña y el Tribunal Constitucional», El Cronista del Estado Social y Democrático de Derecho, 11, 2010.

Rebollo Puig, M., «Elogio de los Jueces», El Cronista del Estado Social y Democrático de Derecho, 15, 2010.

Rodríguez Carbajo, J. R., «Los recursos de casación en la STC 31/2010 sobre el Estatuto de Autonomía de Cataluña», Actualidad Administrativa, 16, 2010.

Tajadura TejadA, J., «La sentencia del Tribunal Constitucional sobre el Estatuto de Cataluña», Temas para el debate, 189-190, 2010.

Tornos MÁs, J., «El Estatuto de Autonomía de Cataluña, y el Estado Autonómico, tras la Sentencia del Tribunal Constitucional 31/2010», El Cronista del Estado Social y Democrático de Derecho, 15, 2010.

Tur Ausina, R.; Álvarez Conde, E., Las consecuencias jurídicas de la sentencia 31/2010, de 28 de junio, del Tribunal Constitucional, sobre el Estatuto de Cataluña. La sentencia de la perfecta libertad, Cuadernos Aranzadi del Tribunal Constitucional/Thomsom Reuters, Pamplona, 2010.

Viver, C., «Els efectes jurídics de la sentencia sobre l'Estatut», Activitat Parlamentaria, Especial sentencia del Tribunal Constitucional sobre l'Estatut d'Autonomia de Catalunya, 2010.

\section{AUTONOMÍA LOCAL}

Aragonés Beltrán, E., «Las haciendas locales en el Estatuto de autonomía de Cataluña», Cuadernos de Derecho Local, 14, 2007.

Argullol Murgades, E., «El desarrollo estatutario de los gobiernos locales en Cataluña», Anuario del Gobierno Local 2007, 2008.

Argullol Murgades, E., «El área metropolitana en la nueva organización territorial», Anuario del Gobierno Local 2006, 2007.

BALlaRín EsPuÑA, M., «El finançament dels governs locals en el nou estatut d’autonomia de Catalunya», Revista d'estudis autonòmics i federals, 6, 2008.

CARrillo, M., «L'administració local en la reforma dels estatuts d'autonomia: especial referència al cas del'Estatut d'autonomia de Catalunya», Cuadernos de Derecho Local, 12, 2006. 
Ferret Jacas, J., «Nuevas reglas de distribución de competencias sobre régimen local», Anuario del Gobierno Local 2006, 2007.

FonT I LlOvet, T., «El Govern Local en el nou Estatut d'autonomia de Catalunya», Activitat Parlamentària, 12, 2007.

Galán Galán, A., «Las leyes de desarrollo básico del Estatuto de Autonomía: el caso de gobiernos locales de Cataluña», Revista d'Estudis Autonòmics i Federals, 9, 2009.

Jiménez Asensio, R., «El Gobierno Local en el Estatuto de Autonomía de Cataluña: primeras reflexiones», Cuadernos de Derecho Local, 13, 2007.

MARTín FernándeZ, J., «La incidencia del nuevo modelo de financiación autonómica en las haciendas locales de Cataluña: autonomía local y reserva de ley», Revista Catalana de Dret Públic, 32, 2006.

Mir i BAGó, J., «La regulación de las veguerías en el nuevo Estatuto de Cataluña», Anuario del Gobierno Local 2006, 2007.

Nel.Lo i Colom, O., «L'organització territorial en el nou Estatut de Catalunya. Gènesi i concreció d'una reforma incompleta», en L'organització del territori: un repte per al seglo XXI?, Barcelona, Fundació Universitat Catalana d'Estiu, 2008.

Pagés Galtés, J., «Las haciendas locales en el nuevo Estatuto de Catalunya», Tributos Locales, 63, 2006.

Pereira i Solé, A., «El régimen local en la reforma del Estatuto de Autonomía de Cataluña», Anuario del Gobierno Local 2004, 2005.

RIDAO, J., «El nou Estatut i l'administració local. Perspectivas i reformes», Revista Catalana de Dret Públic, 34, 2007.

Roig Grau, J. M., «El nou protagonisme del món local», Activitat Parlamentària, 12, 2007.

SANClimens i Solervicens, X., «Perspectivas de l’organització territorial local a Catalunya», Activitat Parlamentària, 12, 2007.

Tornos Mas, J.; Gracia Retortillo, R., «La organización territorial en los nuevos Estatutos de Automomía. En especial, el nivel local supramunicipal en Cataluña», Anuario del Gobierno Local 2008, 2009.

Velasco Caballero, F., «Organización territorial y régimen local en la reforma del Estatuto de Cataluña: límites constitucionales», en Estudios sobre la reforma del Estatuto, Barcelona, Institut d'Estudis Autonòmics, 2004.

Vilalta Ferrer, M., «La financiación local ante la reforma del Estatuto de Autonomía de Cataluña», Anuario del Gobierno Local 2005, 2006.

Vilalta Ferrer, M., «La incidencia del nuevo modelo de financiación autonómica en las haciendas locales de Cataluña: (aspectos económicos)», Revista Catalana de Dret Públic, 32, 2006.

Vilalta Reixach, M., «El Consejo de Gobiernos Locales: la interiorización del régimen local en el nuevo Estatuto de Autonomía de Cataluña», en El Consejo de Gobiernos Locales: la nueva participación de los entes locales en las Comunidades Autónomas, Madrid, Iustel, 2007. 


\section{LENGUA}

Argelaguet i Argemí, J., «La qüestió lingüística en els primers passos del procés de reforma de l'Estatut d’autonomia de Catalunya (1999-2003)», Revista de Llengua i Dret, 47, 2007.

Argelaguet i Argemí, J., El règim lingüistic de Catalunya al nou Estatut d'autonomia: bases per una proposta, Barcelona, Observatori de la Llengua Catalana, 2005.

Barceló i Serramalera, M., «Els drets lingüístics com a drets publics estatutaris», Revista de Llengua i Dret, 47, 2007.

Cabellos Espiérrez, M. A., «La competência em matéria de llengua pròpia en el nou Estatut», Revista de Llengua i Dret, 49, 2008.

Caminal Badia, M., «La reforma dels estatuts i la llengua catalana», Revista de Llengua i Dret, 47, 2007.

Corretja I Torrens, M., «La projecció supraterritorial de la llengua catalana en el nou Estatut d'autonomia de Catalunya», Revista de Llengua i Dret, 47, 2007.

Pla i Boix, A. M., «La llengua al nou Estatut d`Autonomia de Catalunya», Revista d'Estudis Autonòmics i Federals, 3, 2006.

Pla i Boix, A. M., «La llengua en el nou Estatut: avenços i renúncies», El Mirall, $168,2006$.

Pla i Boix, A. M.; Pons Perera, E., «Los derechos y principios lingüísticos en el Estatuto de Autonomía de Cataluña», en Aparicio Pérez, M. A.; Castellá i ANDREU, J. M.; EXPÓsITO, E. (coords.), Derechos y principios rectores en los estatutos de autonomía, Atelier, Barcelona, 2008.

Pons i Parera, E., «Estatuto jurídico de las lenguas en Cataluña», en Pérez FERnÁNDEZ, J. M. (coord.), Estudios sobre el estatuto jurídico de las lenguas en España, Barcelona, Atelier, 2006.

Pons i Parera, E.; Pla i Boix, A. M., «La llengua en el procés de reforma de l'Estatut d'autonomia de Catalunya (2004-2006)», Revista de Llengua i Dret, 47, 2007.

POU i Pujolràs, A., «El català i l'dministració de justícia i el nou Estatut», Revista de Llengua i Dret, 47, 2007.

SAns Socasau, J. L., «L'Estatut i l'occità», Revista de Llengua i Dret, 48, 2007.

SOlÉ i Durán, J. R., «La qüestió lingüística al nou Estatut d'autonomia de Catalunya», Les Noticies de Llengua i Treball, 22, 2006.

Vernet Llobet, J.; Pla Boix, A., «La reforma de l'Estatut d'autonomia de Catalunya en matèria lingüística», Xarxa't, Revista de la Xarxa de Dinamització Lingüústica de la UB, 6, 2005.

Vernet Llobet, J.; Pla Boix, A., «La llengua catalana i un nou Estatut d'autonomia per a Catalunya», Revista de Llengua i Dret, 41, 2004.

\section{DOCUMENTOS}

BAYONA, A. (coord.), Informe sobre la reforma del Estatuto, Barcelona, Institut d'Estudis Autonòmics, 2003. 
CONSEJO CONSULTIVO DE LA GENERALITAT DE CATALUÑA, «Dictamen 269/2005. Sobre la propuesta de proposición de Ley Orgánica por la que se establece el Estatuto de Autonomía de Cataluña y se deroga la Ley orgánica 4/1979, de 18 de diciembre, del Estatuto de Autonomía de Cataluña, las enmiendas y votos particulares reservados para resolver en el Pleno», Revista Española de la Función Consultiva, 7, 2007.

CONSELL DE TREBALL, ECONÒMIC I SOCIAL DE CATALUNYA, Informe sobre la reforma de l'Estatut d'autonomia: limits i potencialitats en relació amb els drets socials i l'economia, Barcelona, CTESC, 2004.

DEPARTAMENT D'ECONOMIA I FINANCES, El Finançament en el Projecte d'Estatut d'Autonomia de Catalunya, Barcelona, Generalitat de Catalunya, 2006.

FAES, «Consecuencias económicas del Proyecto de Estatuto de Autonomía», Observatorio Económico FAES, 4, 2005.

GENERALITAT DE CATALUNYA, Guia comparativa entre l'Estatut de 1979 i el nou Estatut: principals novetats, Barcelona, Generalitat de Catalunya, 2006.

GENERALITAT DE CATALUNYA, El proceso participativo para la reforma del Estatuto de Autonomía de Catalunya, Barcelona, Generalitat de Catalunya-Dirección General de Participación Ciudadana, 2006.

GENERALITAT DE CATALUNYA, Discursos de la delegación del Parlamento de Catalunya: señor Artur Mas i Gavarró (GP de CIU), señora Manuela de Madre Ortega (GP de $S C C$ ), señor Joseph-Lluís Carod-Rovira (GP de ERC), Barcelona, Departamento de la Presidencia, 2006.

INSTITUT D'ESTUDIS AUTONÒMICS, Quadre comparatiu de les propostes de reforma dels estatuts d'autonomia de Catalunya, Andalusia, Comunitat Valenciana, Canàries, Illes Balears i Aragó, Barcelona, Institut d’Estudis Autonomics, 2006.

INSTITUT D’ESTUDIS AUTONÒMICS, Millores introdü̈des pel nou estatut en les competències de la Generalitat, Barcelona, Institut d'Estudis Autonòmics, 2006.

INSTITUT D'ESTUDIS AUTONÒMICS, Propostes d'Institut d'Estudis Autonòmics a la ponència parlamentària sobre la reforma de l'Estatut d'autonomia de Catalunya, Barcelona, Institut d'Estudis Autonòmics, 2005.

PARLAMENT DE CATALUNYA, Informe tecnicolingüistic sobre el text de l'Estatut d'autonomia de Catalunya: juny del 2006, Barcelona, Serveis Jurídics i Serveis Lingüístics del Parlament de Catalunya, Barcelona, 2006.

PARLAMENT DE CATALUNYA, Debat y votació de la Proposta de reforma de l'Estatut d'autonomia de Catalunya: Palau del Parlament, 28, 29 i 30 de setembre de 2005, Barcelona, Parlament de Catalunya, 2006.

Puig Salellas, J. M., Informe de l'Institut d'Estudis Catalans al Parlament de Catalunya sobre la reforma de l'Estatut, Barcelona, IEC, 2004.

***

TITLE: The reform of the Statute of Autonomy of Catalonia. Bibliographic repertoire.

ABSTRACT: This work provides an overwiew on the Spanish literature published on the new Statute of Autonomy of Catalonia. Special focus is placed on studies on Public Law.

RESUMEN: En este trabajo se ofrece una muestra de la bibliografía dedicada a la reforma del Estatuto de Autonomía

UNED. Teoría y Realidad Constitucional, núm. 27, 2011, pp. 
de Cataluña aprobada en 2006. Se han primado los estudios dedicados de manera específica al caso catalán. Los trabajos que abordan la cuestión desde una perspectiva general, centrados en el proceso de reforma estatutaria iniciado en 2006 no se incluyen a no ser que dediquen parte de su atención al Estatuto catalán.

KEYWORDS: Catalonia. territorial structure, autonomy. Statute of Autonomy.

Palabras Clave: Cataluña. distribución territorial. Autonomía. Estatuto de Autonomía.

FeCHA DE RECEPCIÓN: 20.12.2010. FeCHA DE ACEPTACIÓN: 26.01.2011. 